\title{
Evaluation of Teachers' Knowledge of the New Teaching, Learnig and Assessment Methodologies in Selected Primary Schools
}

\author{
Tebogo Mogashoa \\ College of Education, University of South Africa \\ PO Box 392, 0003 Unisa, South Africa \\ Email:mogasti@unisa.ac.za
}

Doi:10.5901/mjss.2013.v4n14p75

\section{Abstract}

The aim of the research was to evaluate teachers' knowledge of new teaching, learning and assessment methodologies. This study was underpinned by constructivist theory. It involved an analysis of the merits and demerits of the implementation of the new teaching, learning and assessment methodologies by teachers in selected primary schools. Qualitative method was used to gather information from the different categories of participants on how teaching, learning and assessment methodologies are implemented. Data were analysed by selecting, comparing, synthesising and interpreting information to provide explanation. It has been established in this study that teachers lack knowledge of learning outcomes and assessment standards. Teachers could not mention the learning outcomes and assessment standards they have planned to address in their lesson plans. The findings revealed that teachers tried to assess learners continuously during lesson presentations. The teacher should know the content, be able to decide on method or teaching approach, level of the learners as well as the learning and teaching support materials to be used in the lesson. Teachers should strive to establish how learners should learn, what teaching and learning activities they will use and how they will check learners' understanding.

Keywords: Curriculum, learning outcomes, assessment standards, involvement, teacher, evaluation and assessment, resources, forms of assessment, participation, relevant, prior knowledge, skills and components.

\section{Introduction and Context of the Study}

The Department of Education has taken a transformative approach to outcomes-based education with emphasis on critical outcomes. Critical outcomes are broad educational goals or a set of skills, attitudes and knowledge that all learners should demonstrate after being exposed to learning and teaching. Curriculum 2005 was then introduced in 1997 and piloted in selected schools countrywide. A pilot study was conducted in Grade 1 classrooms in 270 schools around the entire country between August and November 1997. Then in 1998, the Department of Education introduced Curriculum 2005 in all schools in South Africa. The new curriculum required that educators should be able to understand and respond flexibly to the challenges of the new approaches to curriculum, methods and strategies.

In 2000, Curriculum 2005 was reviewed. The review of Curriculum 2005 was due to an outcry that educators were not coping with the curriculum implementation process. Thus, a Ministerial Committee was established, chaired by Linda Chisholm, which emerged with the Revised National Curriculum Statement (RNCS) (Review Committee on Curriculum 2005, 2000: 21). According to the reviewers of Curriculum 2005, educators needed to be empowered to become successful curriculum mediators by means of effective training opportunities (Review Committee on Curriculum 2005, 2000: 96). The review committee recommended that strengthening the curriculum required streamlining its design features through an amended National Curriculum Statement. The curriculum documents needed to be simplified and workload reduced. Streamlining Curriculum 2005 was the right step taken by the Education authorities in order to assist the educators to implement curriculum effectively.

However, another Task Team was established by the Minister of Basic Education in July 2009 to investigate the nature of the challenges and problems experienced in the implementation of the National Curriculum Statement and to develop a set of recommendations designed to improve the implementation of the National Curriculum Statement. The Task Team came up with a document that it recommended it should replace the National Curriculum Statement and it is called the Curriculum and Assessment Policy Statement (CAPS).

According to Samuels (2009:1), research is designed to solve a particular existing problem so that there is a much larger audience eager to support research that is likely to be profitable or solve problems of immediate concern. It is 
imperative to look at how teachers plan and present their lessons according to the new teaching methodologies. Drotor (2007:3), states that in order to significant, the research needs to exceed the threshold of current scientific work in a specific area. A research study updates previous researches and its development. The investigation might be relevant for theory, practice and future research. The research study can enhance the critical and analytical thinking of students, since in most of the institutions small research studies are an essential component of the syllabus. The research study can give food for thought to new researchers.

\section{Theoretical Frameworks}

According to Terre Blanch (2007:20), refining a research problem involves identifying a theoretical framework upon which to base the research. Theories that influence the research problem as well as the research methods that are used should be stated. This study was underpinned by constructivist theory. It involved an analysis of the merits and demerits of the implementation of the new teaching, learning and assessment methodologies by teachers in selected primary schools. This study was influenced by other teaching and learning theories such as epistemology and ontology, being, which refer to theory of knowledge with regard to methods, and the nature of being, respectively. The focus was on how knowledge or reality is socially constructed.

Constructivism is an epistemology (theory of knowledge), a learning or meaning-making theory that offers an explanation of the nature of knowledge and how human beings learn (Abdal-Haqq 1998:1). An increasingly dominant constructivist view focuses on the cultural embeddedness of learning, employing the methods and framework of cultural anthropology to examine how learning and cognition are distributed in the environment rather than stored in the head of an individual (Duffy 2006:11). As a theory of learning, constructivism is relevant in this study as the researcher wished to establish how learners learn and teachers teach.

Hein (2007:1) mentions that constructivism refers to the idea that learners construct knowledge for themselves, each learner individually and socially constructs meaning- as he or she learns. It maintains that individuals create or construct their own new understandings or knowledge through the interaction of what they already know and believe and the ideas, events, and activities with which they come in contact. Constructing meaning is learning, there is no any other kind of learning other than constructing meaning. Knowledge is acquired through involvement with content instead of imitation or repetition. Teachers must provide the learners with the opportunities to interact with sensory data and construct their own world. Constructivism is thus a theory of learning that likens the acquisition of knowledge to a process of building or constructing. Each learner should actively participate in the learning processes as everyone constructs his or her own knowledge.

Learning activities in constructivist settings are characterised by active engagement, inquiry, problem solving, and collaboration with others (Abdal-Haqq 1998:1). Learning is an active process of constructing rather than acquiring knowledge, and instruction is a process of supporting that construction rather than communicating knowledge (Duffy 2006:2). Learning therefore, is simply the process of adjusting our mental models to accommodate new experiences (Wilson 1996:3). Hein (2007:1) argues that learning is not understanding the 'true' nature of things, nor is it remembering dimly perceived perfect ideas, but rather a personal and social construction of meaning out of the bewildering array of sensations which have no order or structure besides the explanations which we fabricate for them. Rather than the dispenser of knowledge, the teacher is a guide, facilitator, and co-explorer who encourages learners to question, challenge, and formulate their own ideas, opinions and conclusions. Constructivists maintain that when information is required through transmission models, it is not always well integrated with prior knowledge and is often accessed and articulated only for formal academic occasions such as examinations. Learning is an active, constructive process. The learner is an information constructor. New information is linked to prior knowledge. In constructivism learning is an active, contextualised process of constructing knowledge rather than acquiring it.

In order to guide this research, the problem statement is formulated in a form of a question and followed by subquestions. Lock, Spirduso and Silverman (2000:13) indicate that questions are the tools most commonly employed to provide a focus for research study. According to Andrews (2003:69), the research questions must have the potential for being answered in the project or research study to be undertaken. The answers to the main research question and subquestions are aimed at identifying factors that hamper the effective implementation of the teaching, learning and assessment methodologies in primary schools. The main research question is as follows:

$>$ How are teachers implementing teaching, learning and assessment methodologies in primary schools? 


\section{Reseach Design and Methods}

The research methodology of this study was qualitative and inductively based. Qualitative method was used to gather information from the different categories of participants on how teaching, learning and assessment methodologies are implemented. Trochim (2006:1) states that research design provides the glue that holds the research project together and design is used to structure the research, to show all the major parts of the research projects- the samples or groups, measures, treatments or programmes, and methods of assessment- work together to try to address the central research questions. Sridhar (2006:3) defines the research design as a conceptual structure, a blueprint, an outline of what the researcher will do in terms of selection of a problem, formulation of the selected problem, formulation of hypothesis, conceptualisation and research design.

Selection of the schools was based on the type of the school, the learner and teacher population as well as the location of the schools. The target group and population of the study comprised experienced teachers who are teaching Grade 4 and 6 learners, English as First Additional Language (FAL) and have been in the field of teaching for ten or more years. Only five schools in the Gauteng Department of Education's Gauteng North District were invited to participate in the study. These two Grades were selected to investigate how learners cope with their learning activities at the entry and exit levels of the Intermediate Phase.

The above description of the sample is an indication that a purposive sample was used in this research. According to Soanes and Stevenson (2008:1167), purposive refers to "having or done with a particular purpose ". In purposive sampling the researcher must first think critically about the parameters of the population and then choose the sample case accordingly (De Vos, et al 2005:331). Zint and Montgomery (2007:3), state that purposeful sampling is a nonrandom method of sampling where the researcher selects information rich cases for study in depth. Furthermore, Mugo (2011:5) declares that sampling is the act, process, or technique of selecting a suitable sample, or a representative part of a population for the purpose of determining parameters or characteristics of the whole population. The sample is a set of respondents (people) selected from a larger population for the purpose of a survey. In purposeful sampling, we sample with a purpose in mind (Trochim 2006:11). Schools were selected purposefully to the extent that they were regarded as rich sources of the knowledge the researcher intended gathering (Patton, 1990:47). In this study purposeful sampling was used to select for informants with rich information. The sampling involved schools from different socio-economic backgrounds: farm schools, schools from townships, schools from informal settlements as well as the former Model $\mathrm{C}$ schools. This variety of participants enabled an inquiry of how teaching, learning and assessment methodologies are implemented in schools that are different in physical resources, learner and teacher composition and other variables like location, proximity to residential areas, towns and townships. Specific information for schools to be selected was requested at the Gauteng North District of the Department of Education.

According to Voce (2005:6), the primary methods of data collection in qualitative research are observation, interview and focus group discussion. Data collection is simply how information is gathered. In-depth formal observation was used as the main data collection method. Data were also collected through observing and describing the experiences of the participants.

\section{Data Analysis}

According to Michelle (2007:103), qualitative data analysis consists of identifying, coding and categorising patterns found in the data. Bradley (2007:619) declares that once the data have been reviewed and there is a general understanding of the scope and contexts of the key experiences under study, coding provides the analyst with a formal system to organise data, uncovering and documenting additional links within and between concepts and experiences described in the data. Plooy (2007:41) defines data analysis as a process of bringing order and structure to the mass of collected data. Data analysis and interpretation involved the analysis and interpretation of documents related to teaching, learning and assessment methodologies. Data were analysed by selecting, comparing, synthesising and interpreting information to provide explanation. The researcher used the inductive approach to ensure that the research findings emerge from the frequent, dominant or significant themes inherent in raw data generated.

Comparisons were drawn, similarities identified and a discussion of the research was presented. Once the data was generated, the researcher organised the data and discovered the relationships or patterns through close scrutiny of the data. The data were coded, categorised and condensed. The researcher then interpreted and drew meaning from the displayed data. According to Best and Khan (1993:203), the main task in data analysis is to make sense of the amount of data collected by reducing the volume of information, identifying significant patterns and constructing a framework for 
communicating the essence of what the data reveals. The first step to be taken by the researcher involved data organisation. The process also involved grouping of information, coding information of similar kind and genre and describing the information inductive reasoning.

\section{Research Findings and Discussions}

Five lessons were observed, one from each school that participated in this study. Each of the lessons will be described in detail in this section. Comments are made to add to the understanding of the events that unfolded within the classroom environment.

\subsection{Observation of lesson A}

\section{School D}

Name of teacher: Mrs X

Number of lessons: 1

English First Additional Language (FAL)

The teacher wrote LO 1, 2, 3 and 4. There was no indication of what these numbers stood for or represented. The teacher noted the numbers of assessment standards. A variety of resources were stipulated such as workbooks, newspapers and learners' pens. The teacher stated that the lesson was for one week. The teacher introduced the lesson by telling the learners what they were going to do. He asked a few questions to test learners' prior knowledge. He asked learners to mention the names of the pictures on each page. No appropriate examples were given or asked by the learners. The teacher stipulated teacher activities and learner activities. During the presentation of the lesson the teacher read from the book and gave a few explanations. Few learners responded to questions but the majority of the class was quiet. The teacher continuously asked questions. Summative assessment was not done. The questions the teacher asked learners were relevant to the topic.

\subsection{Observation of lesson B}

School A

Name of teacher: $\mathrm{Mr} \mathrm{K}$

Number of lessons: 1

English First Additional Language (FAL)

The various learning outcomes to be covered were written in full, for example, listening, speaking, reading and writing. Assessment standards were also written in full, for example, understand stories, interact in additional language and writing to communicate information. The teacher indicated the various teaching and learning aids to be used such as chards, learners' workbooks' and pictures. The lesson was planned for 40 minutes. The teacher told learners a short story. The teacher asked learners to mention names of the pictures on each page. He gave examples of domestic animals such as dogs, cats and wild animals such as lions and tigers. The teacher stipulated teacher and learner activities in two separate columns, for example, the educator tells a story, and learners listen. He guided the learners through the learning activities. Variety of teaching and learning support materials such as pictures and chards were used and the learners were allowed to touch and use them. There was active participation by learners. The teacher continuously asked questions and the learners responded appropriately. The learners were given an assessment activity to complete in their workbooks. The assessment activities were relevant to the learning activities.

\subsection{Observation of lesson C}

\section{School E}

Name of teacher: Mrs P

Number of lessons: 1

English First Additional Language (FAL)

There were no learning outcomes or assessment standards stated in the lesson plan. The teacher had noted teaching and learning aids such as newspapers and magazines. There was no time frame indicated. The teacher introduced the lesson by asking learners to mention the activities they did the previous day. There was no activity that 
linked the new lesson with learners' prior knowledge. The teacher tried to give a few examples such as when to use present and past tenses in a story. The learners did not seem to understand exactly what the teacher wanted them to do. The only teaching and learning support materials used were the text books the learners had. There was passive learner participation. The teacher asked questions during the lesson: to formulate sentences using new words such as pick, run and collect. Summative assessment was not done. The questions were relevant but the learners could not respond appropriately.

\subsection{Observation of lesson D}

\section{School B}

Name of teacher: Mrs F

Number of lessons: 1

English First Additional Language (FAL)

Only the numbers of the learning outcomes and the assessment standards were written instead of writing them in full. Some teaching and learning aids were indicated such as learners' work books and dictionaries. The lesson was planned for two weeks. The teacher asked learners to mention the activities they did the previous day. There was no clear linking of the new content with learners' prior knowledge. The teacher asked the learners to give examples as she continued with the lesson. Teaching and learning activities that were written in the lesson plan were well followed. The teacher asked learners to use their dictionaries and workbooks. Learners participated actively in the learning activities. The teacher asked learners to formulate sentences with unfamiliar words throughout the lesson. There was no indication of summative assessment. The questions the teacher asked were relevant to the lesson, for example, she asked learners to use connecting words such as "then, and after that".

\subsection{Observation of lesson $E$}

\section{School C}

Name of teacher: Mrs J

Number of lessons: 1

English First Additional Language (FAL)

Learning outcomes were not written in full. Only the numbers for assessment standards were written instead of writing them in full. There was no mention of the resources to be used. The column for the duration of the lesson was blank. The teacher instructed the learners to open their books on a particular page. There was no clear indication of linking the new content with the learners' prior knowledge. The teacher did not give any examples in the presentation of the lesson. The learners were given some activities at the end of the lesson to complete. The only materials were learners' workbooks. Fifteen learners participated actively. Learners were asked questions throughout the lesson. The teacher gave the learners some assessment activities such as using singular and plural forms of nouns. Assessment activities were relevant, for example, when the teacher stated the singular form of a noun, the learners were asked to state the plural form of that particular noun.

\section{Conclusions and Recommendations}

It has been established in this study that teachers lack knowledge of learning outcomes and assessment standards. Teachers could not mention the learning outcomes and assessment standards they have planned to address in their lesson plans. Thus, learning outcomes and assessment standards did not play a significant role in teachers' planning of their lessons. It was evident from data analysis that the time frames set by teachers did not correspond with the number of learning outcomes and assessment standards they planned to address. Although teachers stated a variety of teaching and learning resources, they did not use them in their lessons.

Furthermore, it was found that most teachers lacked skills to link the unknown and the known knowledge learners have in the introduction phase of the lesson presentations. Learners' prior knowledge could not be appropriately tested. This was furthermore, an indication that learners did not understand educators' questions. Moreover, those learners who are taught in second or third language struggle with their learning activities. The findings revealed that teachers tried to assess learners continuously during lesson presentations. However, learners could not respond appropriately to teachers' questions. This was further an indication that the language of learning and teaching was a problem. It has also 
been established that the various forms of assessment were not clearly stipulated in the teachers' lesson plans.

The following essential aspects of a lesson plan should be addressed: lesson details (learning area/subject, grade, theme/topic, date/s, time allocation/duration); learning outcomes and assessment standards as well as the content analysis (teacher activities, learner activities, resources, teaching approaches/methodologies, assessment activities/ strategies/methods/tools). The teacher should know the content, be able to decide on method or teaching approach, level of the learners as well as the learning and teaching support materials to be used in the lesson.

According to Milkova (2007:5), a successful lesson plan addresses and integrates the following key components, that is, objectives for student learning, teaching/learning activities as well as strategies to check student understanding. Furthermore, Milkova suggests the following steps for preparing a lesson: outlining learning activities (topic, what learners should learn, what learners should understand and be able to do at the end of the lesson, what learners should take away from this particular lesson); developing the introduction (starting with the question/activity to gauge learners' knowledge of the subject, developing a creative introduction to the topic to stimulate interest and encourage thinking); planning specific learning activities (preparing several different ways of explaining the materials, explaining the topic, illustrating the topic in different ways, engaging the learners in the topic, relevant real-life examples and learners' needs to enable them to understand the topic better); planning to check for understanding (specific questions to check for understanding, deciding whether learners should respond orally or in writing); developing a conclusion and a preview (summarising the main points of the lesson, reviewing learners' answers to gauge their understanding and explaining anything unclear the following lesson) as well as creating a realistic timeline (narrowing the objectives to two or three key concepts, ideas or skills, estimating how much time each of the activities will take and planning some extra time for each, planning a few minutes at the end of the lesson to answer any remaining questions and to sum up key points, planning some extra activities or discussion questions in case there will be time left, being flexible, that is, being ready to adjust the lesson to learners' needs and focusing on what seems to be more productive rather than sticking to the original plan). The researcher recommends that the Department of Basic Education should provide national templates of lesson plans for all the schools. Teachers should strive to establish how learners should learn, what teaching and learning activities they will use and how they will check learners' understanding.

\section{References}

Abdal-Haqq, I. 1998. Constructivism in Teacher Education: Considerations for those who would link practice to theory. Thousand Oaks. CA: Corwin Press.

Andrews, R. 2003. Research questions. London: Continuum.

Best, J.W and Kahn, J.V. 1993. Research in education. Needham Heights: Allyn and Bacon.

Bradley, E.H. et al. 2007. Qualitative Data Analysis for Health Services Research. Health Services Research. Vol.156: 618-626.

De Vos, A.S. 2005. Combined quantitative and qualitative approach. In De Vos, A.S. (eds). Research at grassroots: For the social sciences and human science professions. $3^{\text {rd }}$ edition. Pretoria: Van Schaik.

Drotor, D. 2007. Thoughts on Establishing Research Significance and Preserving Scientific Integrity. Oxford Journals. Vol. 33:1-5.

Duffy, T.M. 2006. Constructivism: Implications for the Design and Delivery of Instruction. Indianapolis. Indiana University.

Hein, G.E. 2007. Constructivist Learning Theory. Manachusetts. Lesley College Press.

Locke, L.F; Spirduso, W.W and Silverman, S.J. 2000. Proposals that work: A guide for planning dissertations and grant proposals (4th edition). London: Sage Publications.

Michelle, B. 2007. Data Analysis Strategies for Qualitative Research- Research Corner. AORN Journal. Vol. 7: 103-115.

Milkova, S. 2007. Strategies for Effective Lesson Planning. Centre for Research on Learning and Teaching. Michigan City. University of Michigan.

Mugo, F.W. 2011. Sampling in Research. Thoasand Oaks: Sage Publications.

Patton, Q.M. 1990. Qualitative evaluation and research methods. Newbury Park: Sage Publications.

Plooy, G.M. 2007. Communications Research Techniques, Methods and Implications. Claremont. Juta and Co. Ltd.

Review Committee on Curriculum 2005. (L. Chisholm (ed)) A South African Curriculum for the 21st century. Pretoria: Government Printers.

Samuels, P. 2009. The importance of research- Why we do research? London. Sage Publications.

Soanes, C. and Stevenson, A. 2008. Concise Oxford English Dictionary. Oxford. Oxford University Press.

Sridhar, M.S. 2008. Research Methodology: Part 3- Research Design and Plan. Bangalore. Lulu Publishing Services.

Terre Blanche, 2008. Research in Practice: Applied methods for the social sciences. Sandston. Juda Academy.

Trochim, W.M. 2006. Research Methods Knowledge Base 2nd Edition. Cincinnati. Atomic Dog Publications.

Wilson, B. 1996. Constructivist Learning Environments. Englewood Cliffs. Educational Technology Publications.

Zint, M \& Mongomery, N. 2007. Purposeful Sample. London. Sage Publication 